\section{Asthma following occupational exposure to Lycopodium clavatum in condom manufacturers}

\author{
P Cullinan, J Cannon, D Sheril,
} A Newman Taylor

\begin{abstract}
Occupational asthma in two women employed in the manufacture of condoms is reported. The spores of Lycopodium clavatum, used as a rubber dusting agent, were identified as the causative agent.
\end{abstract}

(Thorax 1993;48:774-775)

Occupational and

Environmental

Medicine, Royal

Brompton National

Heart and Lung

Institute, London

SW3 6LR

P Cullinan

J Cannon

A Newman Taylor

343 Ripple Road,

Barking, Essex

D Sheril

Reprint requests to:

Dr P Cullinan

Received 15 June 1992

Returned to authors

29 July 1992

Revised version received

17 September 1992

Accepted 6 October 1992 maize starch dust to prevent adherence. During one shift the patient might load 20000 condoms in a dusty atmosphere and in order to complete the shift she used repeated doses of inhaled salbutamol. Respiratory protection was not worn.

She was referred after four weeks of sick leave. At this time she had a forced expiratory 음 volume in one second $\left(\mathrm{FEV}_{1}\right)$ of $2 \cdot 151$ and $\mathrm{a} \underset{\times}{\stackrel{2}{0}}$ forced vital capacity (FVC) of $2.55 \mathrm{l}$, improving after inhalation of a bronchodilator to FEV $_{1} 2.25$ and FVC 2.60 1. Her histamine? $\mathrm{PC}_{20}$ was greater than $16 \mathrm{mg} / \mathrm{ml}$. She had 흘 immediate skin prick reactions to extracts of $\frac{\bar{D}}{\vec{D}}$ grass pollen, cat fur, house dust, Lycopodium $\stackrel{\mathbb{}}{2}$ clavatum, and maize starch. Specific IgE anti- ڤ bodies to an extract of natural latex were $\vec{\circ}$ absent. Her chest radiograph was normal.

Single blind inhalation tests, with the $\vec{\omega}$ patient wearing latex gloves, were conducted $\rightleftharpoons$ on separate days using a dust tipping method $\stackrel{x}{ }$ in a sealed chamber. ${ }^{1}$ Thirty minutes expo- $\stackrel{+}{\oplus}$ sure to a control dust (lactose) provoked no v change in her baseline $\mathrm{FEV}_{1}$ of 2.201 (fig). Exposure for the same duration to $0.1 \%$ 을 Lycopodium clavatum in lactose provoked $\mathrm{a}=$ $12 \%$ fall in $\mathrm{FEV}_{1} 10$ minutes after the chal- $c$ lenge, and a smaller fall (maximum $6 \%$ ) at 12 ₹ hours. Exposure to a $1.0 \%$ mixture for $30 \overrightarrow{0}$ minutes provoked both an early response (maximum $31 \%$ fall in $\mathrm{FEV}_{1}$ at 15 minutes) and a less marked late response, starting nine hours after the test inhalation with a maximum fall in $\mathrm{FEV}_{1}$ of $14 \%$ at 12 hours. The immediate response was accompanied by $\frac{}{\square}$ nasal symptoms including epistaxis, but no pruritus. Her histamine $\mathrm{PC}_{20}$ remained $\frac{\bar{O}}{3}$ unchanged throughout the period of testing. Four days later she was exposed in the same? way to maize starch, provoking itchy skin immediately after exposure but no asthmatic음 reaction.

Following these findings the patient left the $\frac{\dot{\sigma}}{3}$ factory with complete resolution of her symptoms.

\section{CASE 2}

A 53 year old woman working on the same production line presented with a similar history. She had no past respiratory history but $N$ had smoked until 1965. Seven years after $N$ starting this work she developed a running N nose and itching eyes and, after a further $10 \mathrm{\omega}$ years, shortness of breath and chest tightness. Her symptoms completely resolved when she was not at work. She had immediate skin prick reactions to Lycopodium clavatum and maize starch, as well as to commono inhalant allergens. Shortly after referral she was found to have widespread gastric carci- $\stackrel{\mathbb{Q}}{\Omega}$ noma and further investigations becameo inappropriate.

\section{Discussion}

Lycopodium dust is the spore of the common club moss, Lycopodium clavatum, found commonly across central and northern Europe, Asia, and North America. The lycopodium used in the UK is gathered by hand in China 
or Russia and exported in unadulterated form. Its uniform spores are approximately $25 \mu \mathrm{m}$ in diameter and have high concentrations of fatty acids. The resulting fine, emollient powder is useful in the handling of processed rubber products and in the past was used to dust surgical gloves. The powder has also been used by pharmacists as a coating for pills and suppositories, by homeopaths in the treatment of breathing disorders, and in cosmetics. Lycopodium dust is flammable and is used in small quantities by professional magicians. Recent technological changes have greatly reduced its industrial use but it continues to be used in condom manufacture and by magicians.

The first reported cases of allergy to lycopodium are of occupational asthma in a pharmacist and of rhinitis in a woman using a dry shampoo containing lycopodium. ${ }^{2}$ In 1951 Salen $^{3}$ reported a further 12 cases of asthma, nine in opera singers using a stage makeup based on lycopodium, two in women using dry shampoo, and one in a Swedish boy apparently exposed only to lycopodium spores in the wild. All the subjects had positive skin reactions to lycopodium extracts. In 1988 two of 30 workers at a condom factory in France were reported to have developed occupational asthma attributed to lycopodium. One had a positive skin prick test to Lycopodium clavatum and both showed reductions in peak flow rate immediately after specific bronchial challenge; no late reactions were reported. ${ }^{4}$ In 1989 a 45 year old atopic man was reported to have developed asthma following recreational exposure to condoms coated with lycopodium. ${ }^{5}$ Specific skin prick testing was positive. Although he did not undergo bronchial challenge testing his symptoms resolved when using lycopodium-free condoms.
Those working in the manufacture of condoms are also exposed to rubber and to corn starch, both potential sensitisers. Processed rubber is a mixture of natural latex and various chemicals used as accelerators and preservatives: both may provoke contact dermatitis $^{6}$ and occupational asthma attributed to latex has been described in subjects wearing surgical gloves. ${ }^{7}$ Corn starch may also cause urticaria ${ }^{8}$ and anaphylactic reactions.

In the first patient reported here the combination of a dual response to Lycopodium spores and the absence of a response to corn starch and of specific IgE antibodies to latex make it probable that her symptoms were attributable to lycopodium sensitisation alone. After recognition of the cause of these two cases of asthma in early 1992 the largest producer of condoms in the UK has ceased to use lycopodium in their manufacture; unless new manufacturing uses are found for it lycopodium as a cause of occupational allergic disease should become an historical curiosity.

1 Newman Taylor A, Davies R. Inhalation challenge testing In: Weill $\mathbf{H}$, Turner-Warwick $\mathbf{M}$, eds. Occupational lung diseases: research approach and methods. New York Marcel Dekker, 1982;143-67.

2 Peshkin $M$. Bronchial asthma and other allergic manifestations in pharmacists. $7 A M A 1924 ; 82: 1854-5$.

3 Salen E. Lycopodium allergy. Acta Allergol 1951;IV: 308-19.

4 Catalina P, Chamoux A, Gabrillargues D, Catalina $M$ Royfe $M, W a h l ~ D$. Contribution à l'étude des asthmes d'origine professionelle: l'asthme à la poudre de lycopode. Arch Mal Prof 1988;49:143-8.

5 Juhlin L. Asthma and rhinitis associated with lycopodium spores on condoms. Lancet 1989;i:563.

6 Nutter A. Contact urticaria to rubber. Br $f$ Dermatol 1979;101:597-8.

7 Marcos C, Lazaro M, Fraj J, Quirce S, de la Hoz B, Fernandez-Rivas $M$, et al. Occupational asthma due to latex surgical gloves. Ann Allergy 1991;67:319-23.

8 Fisher A. Contact urticaria and anaphylactoid reaction due to corn starch surgical glove powder. Contact Dermatitis 1987;16:224-5. 